\title{
Study on The Visual Construction of Chinese Contemporary Photography and Traditional Culture Elements
}

\author{
Chaojie Wei \\ Huanghe Science and Technology College, \\ Zhengzhou, China
}

\begin{abstract}
From the "reform and opening-up" of the 1980s till building a harmonious society today, Chinese photography always launches the interaction with contemporary social life in the great change, and seeks more development space and possibilities for the healthy development of photography and the mutual promotion between photography and the society through the positive interactions. Under such historical background, contemporary photographers should combine personal ideal and feelings with people's ideals and feelings, and focus on the development trend of the whole human society. Based on the inheriting of the excellent national culture, they should pursue and display the national cultural spirit which is more suitable for modern human existence and has typical modernity quality, and thus achieve the visual construction from reality to concept.
\end{abstract}

Keywords-Traditional Culture Elements; Visualization; Construction

\section{THE RISE OF CHINESE CONTEMPORARY PHOTOGRAPHY}

In 1980s and 1990s China, under the government's policy of firmly pushing reform and opening-up and developing economy continually, China has entered into a sound and rapid process of modernization, and market economy has been in full swing, following the more prominent variety of social conflicts. The progressive acceleration in the process of industrialization caused the destruction to environmental resources. The gap between rural and urban areas was growing. Numerous peasants have left their land and home to run in their way of working. These have caused a series of social problems. The pattern of social interest distribution was subjected to unprecedented impact, and people's thoughts and psychology were in inflation and challenge. With the not so well-established supervisory mechanisms of the reform and opening-up, some photographers have revealed the hidden realistic problem to warned people to pay attention to the balance of development by photos through their own efforts. For example, Xie Hailong's documentary photography series the "Hope Project" [Fig.1] drew great attention to the backward education from the society and really changed the education problems in many remote mountainous areas.
Freelance photographer Lu Guang's documentary photojournalism "The Camera Don't Lie" [Fig.2] and [Fig.3] was the real photographic survey of AIDS in Shangcai, Henan Province, and was spread through all different channels, which caused great international attention and the attention from China government to take active measures to remedy and control this situation. From the summer of 1989 to the spring of 1990, photographer Xu Yong has spent more than one year to shoot Hutong in Beijing and published the photography collection "101 Images of Hutong". Hutong is the living gallery of Beijing people's daily life, the important component of Beijing city life, and the important historical site of Beijing, containing unique humanistic and historical value. It is because of photographer Xu Yong's "101 Images of Hutong" that the Hutong culture of the old Beijing could be saved. During this period, there are many photography works of other excellent photographers like Hou Dengke, Hu Wugong, Zhao Zhenhai, Chen Jin, Jiang Jian, etc. of course. Their works all reflected the awareness of social responsibility of the documentary photography in fact. The root of this kind of thinking is every man has a share of responsibility for the fate of his country, which emphasized the active participation in the society and is the embodiment of the Confucian thoughts in Chinese traditional culture that create value for our society. Therefore, under such situation, many excellent photographers have appeared in China in the late 20th century, which made Chinese contemporary photography develop vigorously.

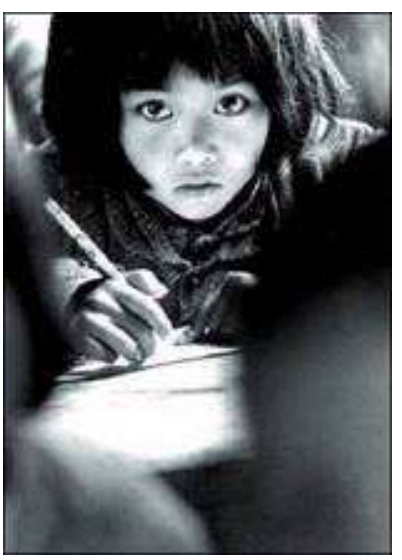

Fig. 1. Hope Project 


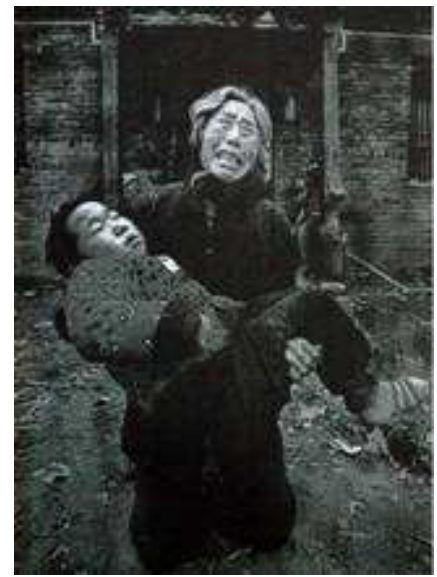

Fig. 2. The Camera Don't Lie

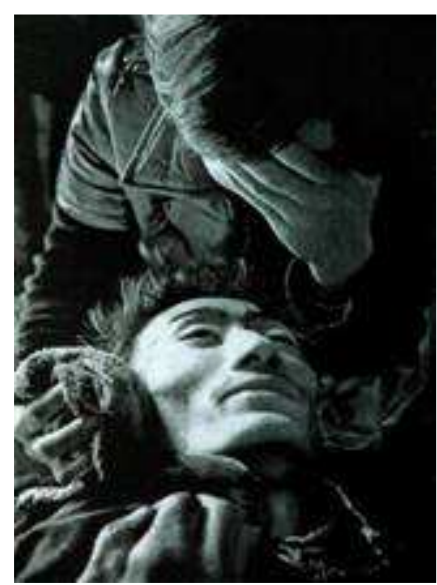

Fig. 3. The Camera Don't Lie

\section{RESEARCH ON THE VISUAL CONSTRUCTION OF NATIONAL CULTURE ELEMENTS FROM THE TRANSFORMATION OF CONTEMPORARY PHOTOGRAPHY}

Along with the development and change of world politics and economy since the 1990s, great changes have taken place in Chinese society. The impacts of the changes occurred was deep and extensive, not only changed the physical appearance of contemporary Chinese society, but also influenced people's life style and ideas greatly. Especially the culture development has displayed the trend of diversification, visualization, multimedia and consumerization, which is closely linked to human behavior and thinking. People's aesthetics and value were impacted by multiple dimension trends. How to adapt to and finish this kind of transformation is the question in front of people, and the development of photography art is no exception.

Along with the decline of documentary photography, conceptual photography emerged at the right moment as the relay of culture. The emerging of conceptual photography was related to the rapid Chinese economic development. The great changes in the urban environment itself and the fast expansion of media were the important external conditions that promote the emergence of conceptual photography. This kind of situation will make the acute artists intuitively recognize the pressure of realistic environment, and produce the expressive impulse to talk and compete with this pressure by the description of his photos intangibly. Compared with traditional documentary photography, conceptual photography is quite different. Conceptual photography displays the analysis of human condition through the medium of photography, proposes a series of interesting topics and leaves people with the thinking on a deeper level. Conceptual photography doesn't give answers, but points to the possibilities to make the viewers to comprehend by themselves. Contemporary artists are not contend with the traditional visual pleasure from viewing the photos, but pay more attention to convey certain concept and meaning really. The internal factor of photographic transformation is that contemporary photography should make breakthrough in theme, subject, language, form and so on. Prompted by internal and external conditions and causes, documentary photography, which emphasizes instant record and truly objective, has the functional transformation. From the measure of publicity and record, photography has changed into the tool of social intervention and culture creation. This transformation is hard to achieve, and also takes conceptual photography as the major component.

Conceptual photography was established at the beginning of 1990s. It can be divided into images, device images, conceptual images and multimedia images, etc. It can also be divided into two periods in time. The first period is from 1993 to 1997 , which is the embryonic period of Chinese conceptual photography. During this period, many artists created some conceptual images spontaneously, but there is no the term "conceptual photography". For example, Xu Hui's "Visit Lei Feng", Wang Qingsong's "Standard Photos", Zhuang Hui's "Group Photos", and Zhao Mandi's "Never Forget Class Conflict", and so on. The second period is from 1997 till now, during when formed the stylized features of conceptual photography. Since 2000, conceptual photography has reached a new stage of photography and a period of fast development. In this period, by using photography as a medium, conceptual art has changed into conceptual photography based on concepts. In business, in order to meet the needs of easy transaction of conceptual art, photos have become the major form of conceptual artistic works. More young artists who are specialized in painting and sculpture have entered the field of conceptual photography, such as the Gao Brothers, Wang Qingsong, Qiu Zhijie and so on. However, figures from photography were not too much. Representative figures are Liu Zheng, Xu Yong, Ling Fei in France and Wang Xiaohui in Germany and so on.

When talking about conceptual photography, we must start from Liu Zheng, the most representative figure of Chinese conceptual photography. During his decades of photography career, we can have a glimpse on the passion and bewilderment of Chinese conceptual photography from its beginning to the first developing step. "At that time, photography is a way to take record. People don't care about the kind of photography I liked. I was depressing all the time." said Liu Zheng. Besides work, he sought the type of 
photography imagined in his mind desperately. He felt that there must be a kind of photography that is beyond record and describes the concept of certain things. In 1996, Liu Zheng and Rongrong planned and created the magazine "New Photography" by rising money. In the preface of the magazine, Liu Zheng wrote, "Once concept is combined into images, everything in front of us was suddenly enlightened."

Liu Zheng began take photos for his series of photography "Countryman" in 1994. "Countryman" employed folklore Chinese realistic portrait to list all sorts of strange Chinese people living in this period. These images was likely to make different people living in Chinese reality more unknowable, and made it more difficult to predict what kind of reality we are living in. The reason why "Countryman" is considered as conceptual photography is that Liu Zheng employed a presupposed concept to catch images in reality. Thus there is a strong subjective induction, taking the collection of numerous works as the display of artistic desire.

Hong Lei is one of the most distinctive conceptual photographers. In his works, Chinese traditional culture is always the major resource of his realistic thinking. His "Chinese Scenery • Wind • Water • Fire" [Fig.4] and [Fig.5] takes gardens, one of the major forms of traditional Chinese literati culture, as the theme. Chinese gardens are the imitation of nature, as well as the surpassing of nature. At the same time, it is also the cultural dream and the standard of aesthetics. Gardens owned privately before have changed into public gardens open to the public in modern Chinese society, which became the organic competitions of modern city. However, in the photos of Hong Lei, he made it into a culture sample or fossil where no one exist, and then sent it back into past through images, displaying its symbolic meaning as culture index. The intangible and alienate, pretty and strange, gloomy and cold, and secluded of the gardens were employed to express the constraint of history and the transcendence of tradition. With wind, water and fire, traditional gardens evolved into a beautiful tragedy. The distinctive artistic style of Hong Lei is to display his death complex in the imitation of Chinese ancient painting. Unsatisfied and unharmonious elements like bright and gloomy, quiet and strange and so on were melting together in the photos, which conveyed the modern explanation of Chinese tradition. If the attitude of Lang Jingshan toward classical Chinese traditional culture is to inherit and carry forward, the attitude of Hong Lei is to reflect and criticize.

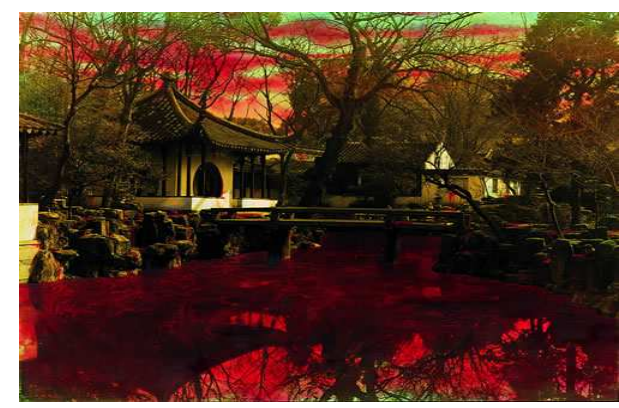

Fig. 4. Chinese Scenery · Wind · Water · Fire

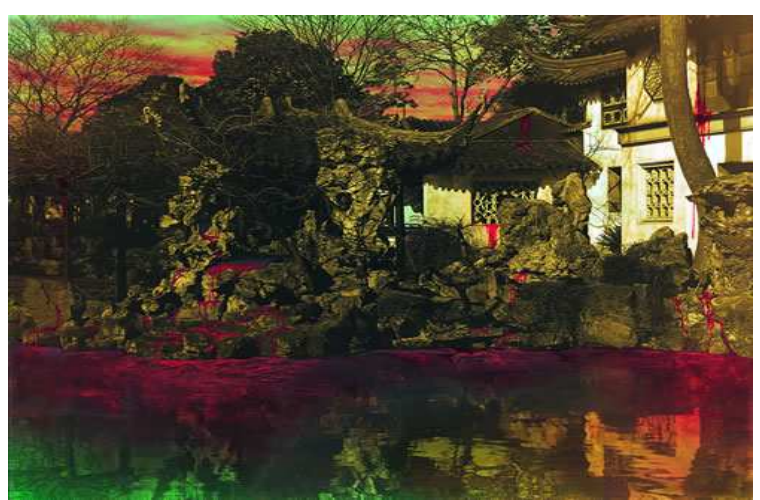

Fig. 5. Chinese Scenery · Wind · Water · Fire

Chinese contemporary photography came into being in the period of transformation from Chinese agricultural society to industrial society, or directly in the process of transformation to post-industrial society, lacking the mature industries as in the western countries. Western conceptual photography was born in a new kind of city culture separated from the city. Things were different for China. Chinese conceptual photography was born in the transformation from rural area to the city. The conceptual photography in 1990s' always reflected the great changes in human hearts in the transformation from rural areas to the city, including the changes of the city. No matter the city architecture or human in the photos, there was a distinct combination of rural areas and the city.

Of course, because of the variety of display methods, contents and concepts in conceptual photography, it has been mixed with many superficial expressions and low-wits rumination, or made unrealistic fuss about nothing. The conceptual photography works that are separated from tradition, reality and value orientation are abnormal morbid. They escaped from traditional culture and reality, and were disrespectful for photography. As said by Bao Kun, "In order to move people for any artistic works, there should not only be the perfect and distinct artistic form, but also the appeal of certain values behind, which is the creator's thoughts.'”[3]

As for the sophisticate and restless situation of Chinese contemporary photography, the fundamental reason in the writer's mind is that there lacks culture support, especially lacks the systematic understanding of national traditional tradition. China has thousands of years' history of national culture, and the cultural connotation is rich and various. These are beneficial to us today. However, some conceptual photographers totally deny or abandon Chinese national culture, which is absolutely wrong. In my opinion, there is an inexhaustible treasure for the visual construction of contemporary photography if it depends on our national excellent culture.

\section{III. “NATIONAL CULTURE” IS THE “COMPASS” OF CONTEMPORARY CONCEPTUAL PHOTOGRAPHY}

National culture is the collective memory and spiritual ballast of the history creation for a country and a nation. In 
"Chinese People Should Take a Rational Look at the Chinese Renaissance", the scholar Zheng Yongnian thinks that, "There is no rise of culture in China. The rise of economy has not brought the renaissance of culture. On the contrary, traditional culture is disappearing rapidly, and is replaced by business culture and fast food culture. It is even harder to find the trace of tradition in China after the baptism of industrialization and urbanization. Even though some people advocated the study of classical tradition such as "The Four Books and The Five Classics", it is inharmonious with the whole social changes. No one believes that this kind of effort will preserve tradition culture, let alone renaissance. In some degree, China has gradually turned into a civilization that loses traditional culture." [4]

In response to this problem, Mr. O Huang director of national photography center in the Culture Ministry of France, said, "At present, the rapid (probably too fast) social changes in China is threatening the nation, culture and the tradition of the ancestors. Under such circumstance, the responsibility of recording and preserving culture and tradition is extremely urgent." His words are not exaggeration just to scare people. In front of the overall situation of global integration, the more realistic and urgent subject is how to inherit and carry forward the excellent culture and tradition and form our own characteristics for Chinese photography in the occasion of modernization and going to the world.

Look around the world, the employment of national culture in contemporary photography is the developing trend of world visual culture. This also proves the old saying "What belongs to the world belongs to the nation; and without a nation, there is no world." As a qualified photographer, one should create from the historical perspective, thinking of our times with a strong sense of national responsibility and mission and enrich our creation thoughts with national culture. At the same time, the visual construction of national culture in photography is a kind of promotion to the development of photography art itself.

Of course, visual construction of national culture in contemporary photography is also directional and selective. It is because that in the long period development process of national culture, there are some dross elements more or less. If we don't think and filter and use them in contemporary photography, there will be some absurd problems, even some restrained and transformational things, and things that reversed the black and white. This is what we don't want to see.

From the "reform and opening-up" of the 1980s till building a harmonious society today, Chinese photography always launches the interaction with contemporary social life in the great change, and seeks more development space and possibilities for the healthy development of photography and the mutual promotion between photography and the society through the positive interactions. Under such historical background, contemporary photographers should combine personal ideal and feelings with people's ideals and feelings, and focus on the development trend of the whole human society. Based on the inheriting of the excellent national culture, they should pursue and display the national cultural spirit which is more suitable for modern human existence and has typical modernity quality, and thus achieve smoothly the visual construction of contemporary photography.

\section{NOTES}

[1] Wang Hailong, Visual Anthropology, Shanghai Literature and Art Publishing House, 2007, P4.

[2] Wang Hailong, Visual Anthropology, Shanghai Literature and Art Publishing House, 2007, P16.

[3] Bao Kun, View and Viewing, China Federation of Literary and Art Circles Publishing Corporation, 2009, P136.

[4] Singapore, Lianhe Zaobao, July 11, 2006.

\section{REFERENCES}

[1] Zhou Xian. Diversion of Visual Culture. Peking University Press: 2008.

[2] Bao Kun. View and Viewing. China Federation of Literary and Art Circles Publishing Corporation: 2009

[3] Wang Hongjian. An Introduction to Art. Culture and Art Publishing House: 2003

[4] Gu Zheng. The World History of Photography. Zhejiang Photography Press: 2009. 